\title{
Understanding Inhabitants' Spatial Experience of the City of Doha through Cognitive Mapping
}

Article in Open House International · December 2013

CITATION

1

3 authors, including:

\section{Ashraf M. Salama}

University of Strathclyde

99 PUBLICATIONS 252 CITATIONS

SEE PROFILE
READS

13

Fatma Khalfani

Qatar University

4 PUBLICATIONS 6 CITATIONS

SEE PROFILE 


\title{
14. UNDERSTANDING INHABITANTS' SPATIAL EXPERIENCE OF THE CITY OF DOHA THROUGH COGNITIVE MAPPING
}

\section{Ashraf M. Salama, Ahood Al-Maimani, and Fatma Khalfani}

\begin{abstract}
Despite the current fast track urban development process that characterizes the city of Doha, very few studies have addressed several important growth aspects, including the examination of the way in which its inhabitants comprehend and react to its built environment and the resulting spatial experience. This paper examines inhabitants' spatial experience in the city by applying cognitive mapping procedures coupled with an attitude survey. 108 responses were received, analyzed, and classified in three categories a) living, working, and visiting patterns; b) comprehension of home range, home zone, and movement; and c) ethnic affiliation: Qataris and other Arab expatriates. The findings contribute to an in-depth understanding of the inhabitants' spatial experience. The study concludes with an emphasis that by establishing knowledge generated from research findings that are derived from direct experience of inhabitants including movement patterns and the rhythm of geographical locations within the city, the various aspects of how certain areas work within the urban structure of the city can be elucidated.
\end{abstract}

Keywords: Spatial Experience, Doha, Urban Mobility, Home Range, Home Zone, Cognitive Mapping.

\section{INTRODUCTION: EXPERIENCING DOHA'S URBAN OPEN SPACES}

The city of Doha is experiencing continual rapid growth with new or emerging urban nodes and centres, housing developments, and a wide spectrum of mixed-use interventions. Little attention, however, has been paid to several important growth aspects, including the examination of the dialectic relationship between the city inhabitants and the urban environment, the understanding of the way in which the inhabitants comprehend and react to its built environment and the resulting spatial experience, as well as their attitudes toward newly urbanised spaces (Salama and Wiedmann, 2013). Utilising techniques derived from the field of 'Environment-Behaviour Research,' this paper provides an analytical understanding of how the residents of Doha identify with their surroundings, how they spatially experience the city, and how they relate to selected key spaces or urban areas. Based on applying cognitive mapping procedures together with an attitude survey the paper explores urban areas in the city as perceived and experienced by various groups of residents.

Different cultural groups, age groups, and genders appear to experience the city of Doha, its overall urban environment, and its urban open spaces in very different ways (Salama and Gharib, 2012). These groups have different spheres of experience, interaction with, and interest in the spaces; the purpose for which they visit and interact with them varies dramatically. In addition, due to factors related to their cultural background, age, or gender, their understanding and perception of the city is quite different; this is generally based on the places where they live, work, visit, and how they move about the city. Their perception of the overall urban environment is defined by their personal experiences and relates to what different spaces within the city have to offer (Salama, 2011 ). While some inhabitants may enjoy key attractions such as the Corniche Waterfront Park (Figure 1) or Al Bidda Park (Figure 2) or the restored and rehabilitated traditional market, Souq Waqif (Figure 3), others may prefer the new, more exclusive, developments such as Katara Cultural Village or The Pearl Qatar development (Figure 4). Some may even like the dense urban areas and spaces that are characterised by affordable merchandising and shopping areas, while still others prefer open green spaces that satisfy their leisure time and recreational needs and those of their children.

Examining how the city inhabitants experience it and its open spaces should go beyond interviewing a small group of inhabitants as this may support what is already self-evident. Rather, research techniques such as cognitive mapping and attitude surveys are needed to assess and interpret the way in which inhabitants comprehend dif- 


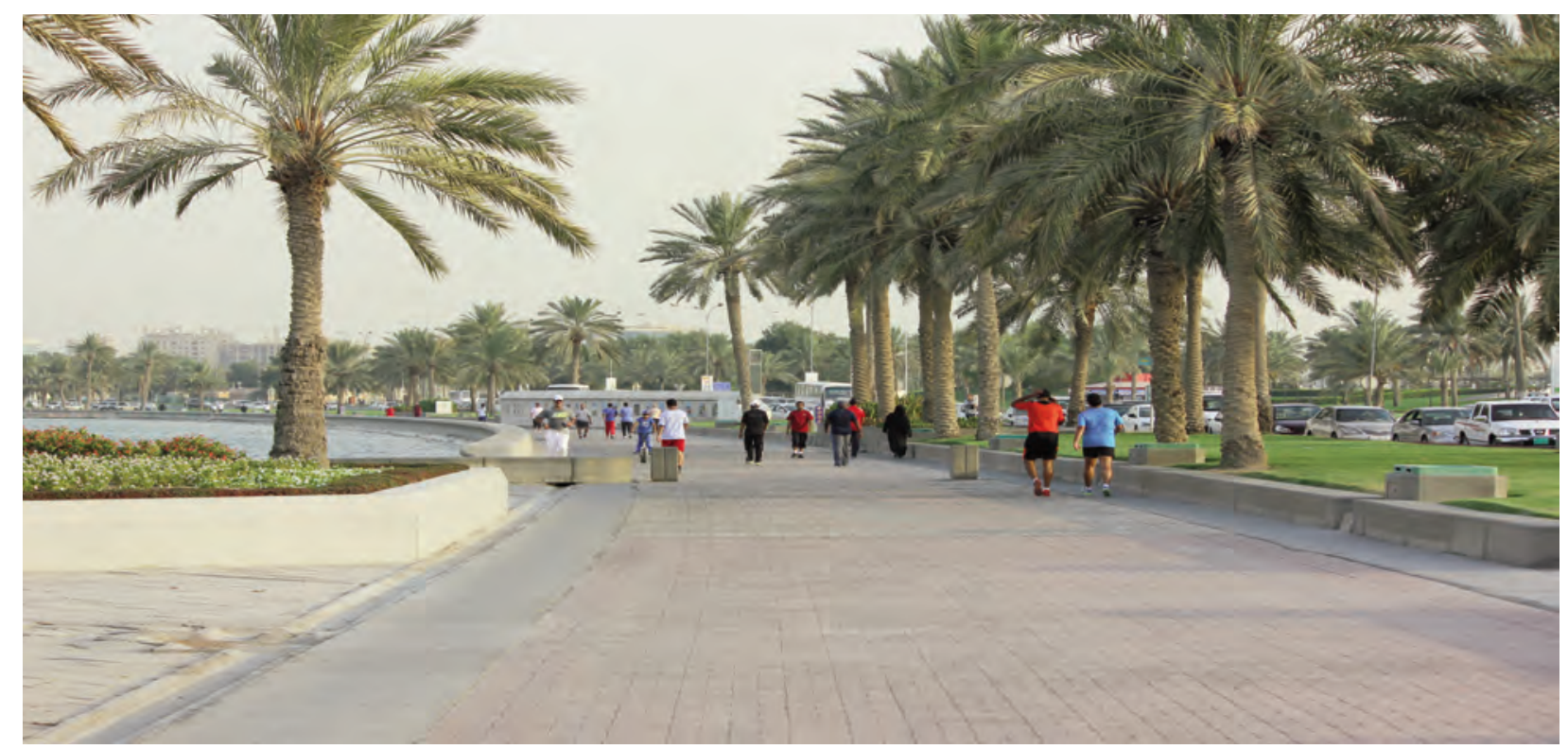

Figure 1. The waterfront promenade of the Corniche road. (Source: Authors).

ferent locations and their movement experiences. In this respect, cognitive mapping is utilized a process composed of a series of psychological transformations by which individuals acquire, code, store, recall, and decode information about the relative locations and attributes in their everyday spatial environment (Downs and Stea, 1973). Thus, a cognitive map is a mental device that codes and simplifies the way in which the spatial environment is arranged (Ormrod, 2011 ). In essence, cognitive maps are a mental representation of physical locations.

When reviewing and analysing how the city of Doha is experienced by its residents and users, two critical urban elements appear as predisposing factors governed by the spatial perception of the structure of a city; these are the understanding of geographical locations and urban mobility or movement within the city, and the way in which people relate to both.

Geographical locations can be exemplified by prominent or well-known places that influence people's perception of the city, such as the areas where they live, work, visit, entertain, etc. Two types of areas appear to have a strong influence on how people perceive geographical locations; these are referred to as the 'home zone' and the 'home range.' Home zone and home range are phenomena that relate to the concept of territoriality. They have been discussed in the writings of theorists and researchers whose main driver is to establish links between the physical environment and social

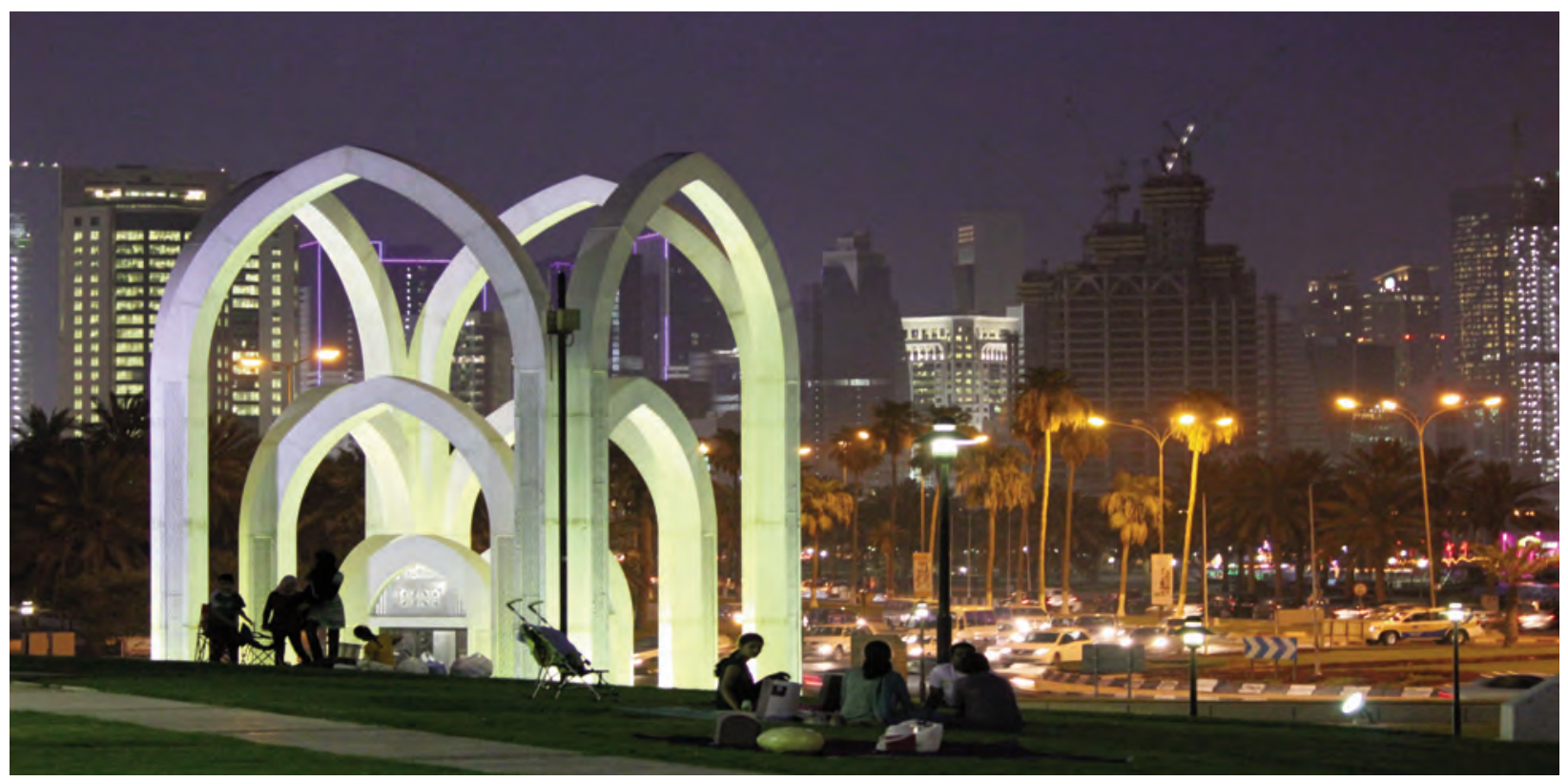

Figure 2. Al-Bidda Park, one of the key attractions in the city of Doha. (Source: Authors). 


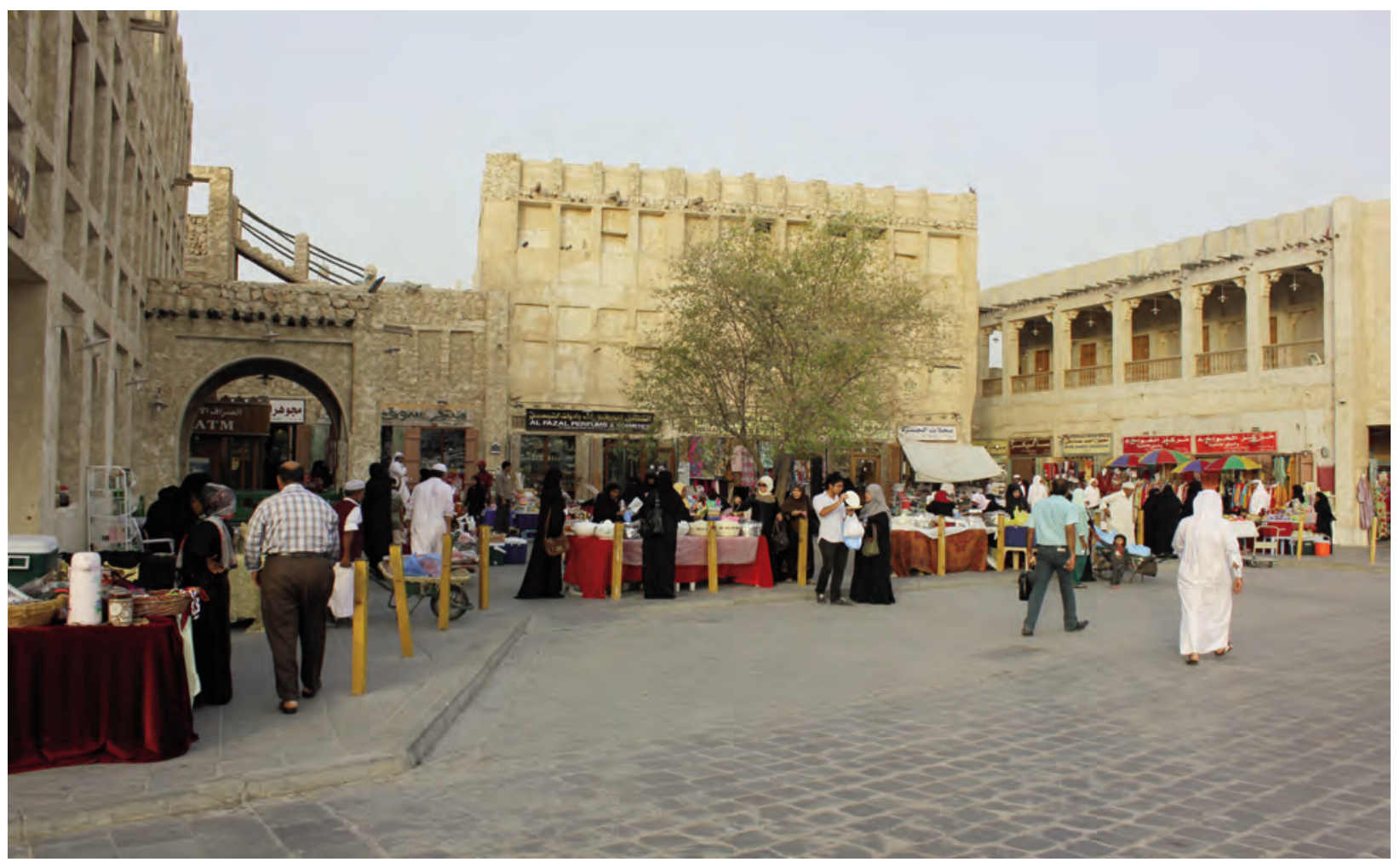

Figure 3. The restored traditional market, Souq Waqif. (Source: Authors).

behavior (Altman, 1975; Rapoport, 2006; AbdelHadi, ElNachar \& Safieldin, 2011). On the one hand, the home zone is a phenomenon that is related to an environment with minimal need for modes of transportation; such locales can be easily accessed on foot and thus engender a sense of ownership and belonging among the residents of its inner streets and public spaces. On the other hand, home range is a concept more concerned with a holistic mental image of the entire residential environment, irrespective of its scale and size. It places emphasis on the perceived territorial and

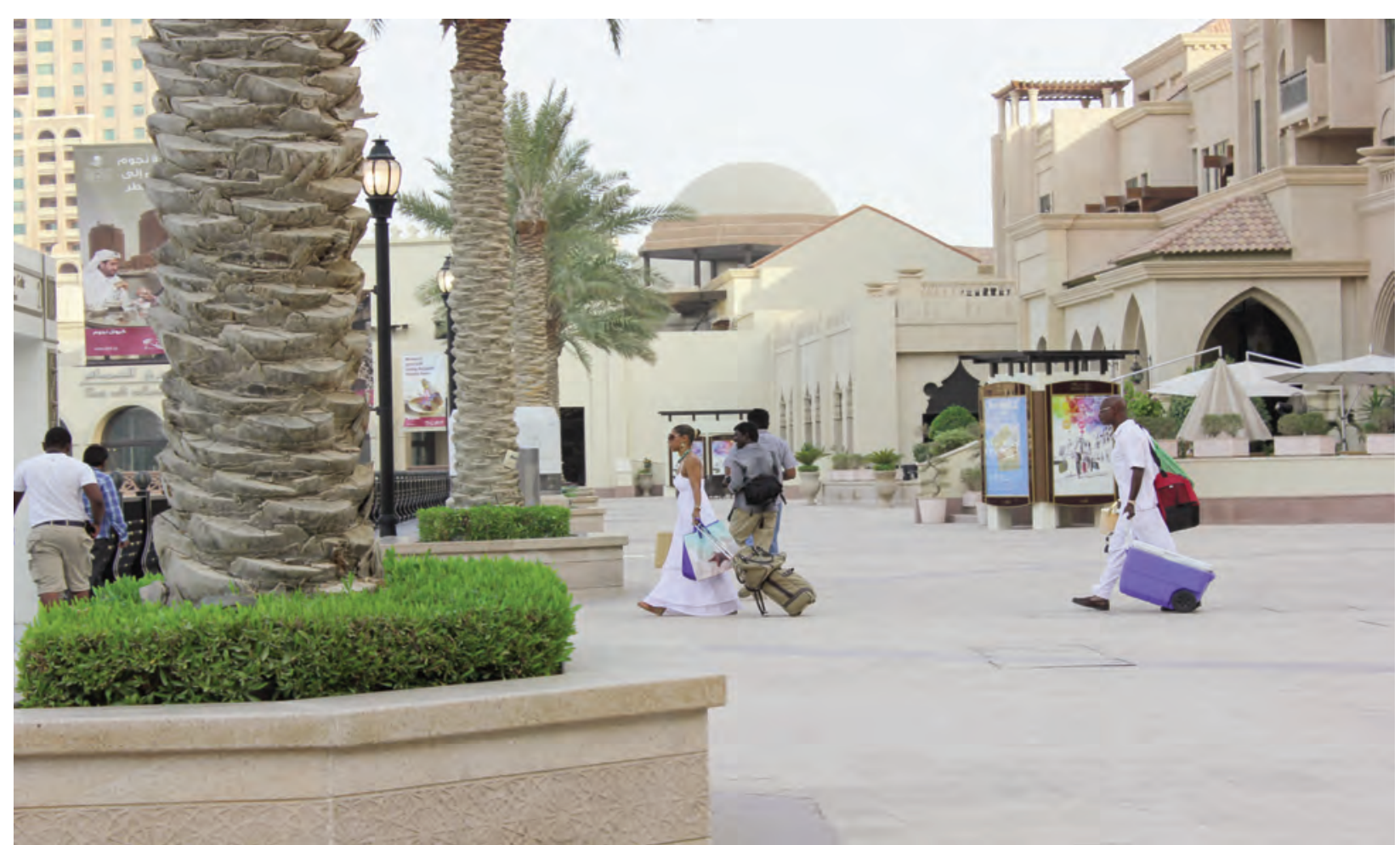

Figure 4. The Pearl Qatar, one of the exclusive developments on the northwestern periphery of the city. (Source: Authors). 
geographical boundary for the inhabitants as individuals and in groups.

For urban planning and design as branches derived from the domains of social sciences and engineering, a city is a fluid dynamic system that keeps evolving or changing. In any city material and non-material inputs and outputs flow in, out, and within; a process that creates movement and mobility. Movement and urban mobility have been viewed in the historical and contemporary urban literature as important aspects of successful cities. On the one hand, historical writings in the field have attempted to address social and behavioral issues in relation to movement (Burgess, 1925; Sorokin, 1927). On the other hand, contemporary writings have focused on the idea of networks in relation to the spatial structure (Geyer and Kontuly, 1996).

The current accelerated spread of urban areas in Doha has led to extensive urban sprawl and the formation of additional larger urbanised areas and has resulted in the emergence of agglomerations and the notion of greater and expanding city boundaries or metropolitan areas. Such areas can be defined on the basis of how far from and how long it takes to commute to the city core, or from living areas to work areas, and public places. Understanding urban mobility or movement patterns within the city is crucial to understanding the operational principles that go beyond a single urban locality. Movement is also affected by the new spatial patterns and the spatial distribution of functions and uses. By developing an understanding of people's movement patterns and the rhythm of geographical locations within the city, the various aspects of how certain areas work within the city's urban structure can be identified, analysed and explained.

\section{A METHODOLOGY FOR UNDERSTANDING THE INHABITANTS' SPATIAL EXPERIENCE IN THE CITY OF DOHA}

In order to examine the experience of the city's inhabitants in terms of movement and their comprehension of the city in terms of where they live, work, entertain, and what travel routes they use, a survey questionnaire was developed with two objectives in mind. The first aim was to gather data for interpretations of how the city is experienced based on the inhabitants' reactions to certain parameters, rather than the utilising more standard practice of reading and interpreting the city based on analyses of reports by specialised professionals or observers. The second objective was to investigate the way in which inhabitants perceive move- ment in the city in relation to the geographical locations most important to them such as living areas, work areas, and the public places they frequent.

Eighteen undergraduate students were asked to respond to the survey questionnaire, and then distribute it to ten people such as relatives and neighbors to solicit responses. The process required architecture students explaining the survey to the participants including its purpose and the nature of the questions. The questionnaire provided a map of greater Doha and included queries about basic information related to the gender, age, and cultural background of the participants; they were required to name them and indicate the area where they live and work on the map (Figure 5, Table 1).

Participants had to select the three public spaces that they frequented the most, as well as indicate the routes they take from their residence to their workplace, and the routes taken to the most visited public spaces on the map. Relying on cognitive mapping procedure, the questionnaire required participants to mark the home zone and home range on the map. Home zone was defined to the participants as the immediate context around their homes, which reflects a shared or collective hypothetical ownership of communal space or area while home range was delineated as the respondents' mental image, based on their understanding of what defines such an environment and their perception of its boundaries, of the entire residential environment or district around their home.

Over $50 \%$ of the targeted population responded to the survey with a total of 108 responses received. The comprehension of movement, home zone, and home range was an integral component of a larger study conducted by architecture students of the class of 2012 as part of an elective course on Post Occupancy Evaluation,

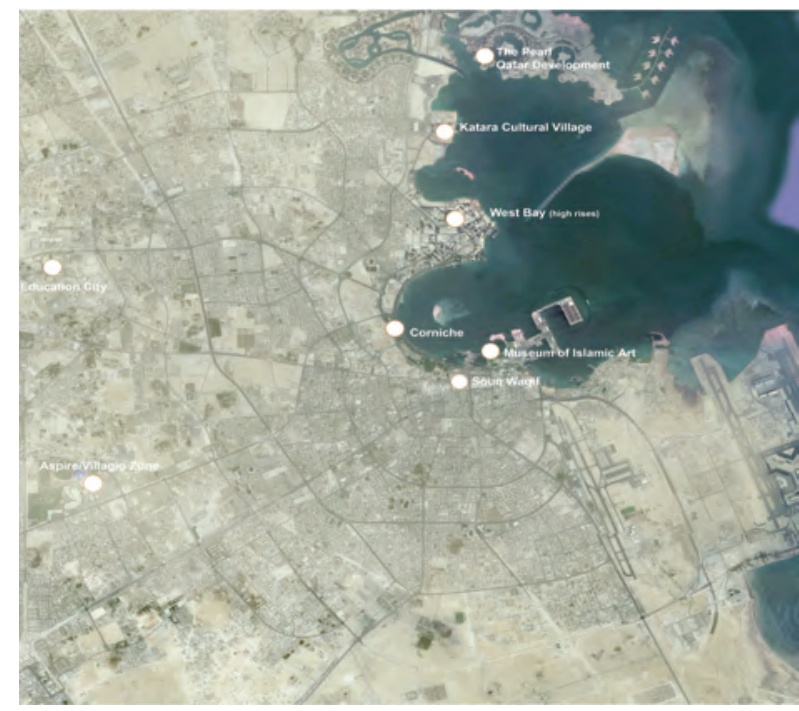

Figure 5. Fig. 5. Map of greater Doha and the spaces investigated. (Google Earth, 2012). 


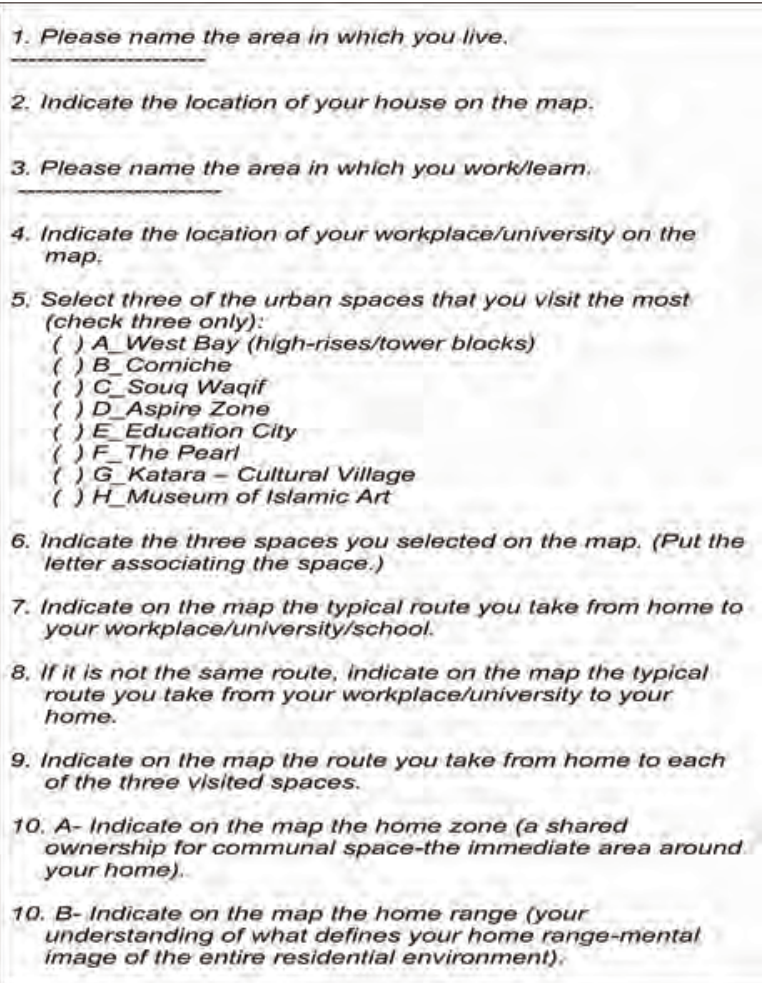

Table 7. List of questions included in the questionnaire to examine movement experience and comprehension of geographical locations. (Source: Authors).

offered in the spring semester at the Department of Architecture and Urban Planning at Qatar University, and delivered in the Spring 2012.

The profile of the respondents was representative of a wide spectrum of people, from different cultural backgrounds: $65 \%$ of the respondents were Qatari nationals while 35\% were expatriate professionals, mainly from neighbouring Arab countries. Sixty-nine per cent of the respondents were between 20 and 40 years old, the majority of whom $(65 \%)$ were female. While the respondents' profile was reasonably diverse, it should be noted that Americans, Asians, and Europeans represent other cultural groups that also form an important component of the city's expatriate residents, were not included in the survey. Therefore, while the responses from the sample group and the population they represent cannot be generalised to represent the whole city, they offer important insights into the understanding of certain preferences and movement patterns within the city as they relate to the participants.

\section{ANALYSIS OF RESULTS AND DISCUSSION}

Utilising frequency, cross-tabulation, and cumulative mapping procedures for the total number of respondents and for groups of Qataris and Arab expatriates, results were categorised into three bands that pertained to: a) living, working, and visiting; b) home range, home zone, and movement; and c) ethnic affiliation: Qataris and other Arab expatriates.

\section{Living, Working, and Visiting}

The areas where the participants in the survey live vary greatly. However, three areas or districts stand out from the responses; these are Mamoura, Gharrafa, and Khraitiyat: 9\% of the respondents live in Mamoura district, while Gharrafa and Khraitiyat districts each received $8 \%$ of the responses. This result corresponds with the overall profile of the respondents: for example, the Mamoura district is characterised by a mix of Qataris, who reside in privately owned homes, and other Arab nationals who live in villas and low-rise apartment buildings typically rented by employers for their expatriate workforce. In contrast, the Gharrafa and Khraitiyat districts, located in close proximity to the northwestern peripheries of the city, are primarily characterised by Qatari homes thus reflecting their preference for living on the outskirts and periphery of the city.

In terms of the areas where survey participants work, four areas are clearly identified from the responses: $32 \%$ of the respondents work in the Tarfa district while 12\% work in the Dafna area. This may be due to the fact that the former is characterised by the presence of the Qatar University campus, while the latter represents the emerging business and financial district in the West Bay area. The Al Sadd and Shaqab districts received 7\% and $6 \%$ as respectively as workplace areas. This suggests that while the Al Sadd area represents a more traditional business district, close to the city centre core, the Dafna or West Bay financial area has already started to attract more businesses and employees. Further the Shaqab area, which is dominated by the presence of Qatar Foundation and its various subsidiaries such as Education City, The Convention Centre, Sidra Hospital and Qatar Science and Technology Park, does not represent the workplace zone for most of the survey participants who are mainly Qatari and Arab nationals.

Four public spaces appear to compete for the most frequently visited urban open spaces: Katara Cultural Village received $58 \%$ of the total responses, followed by Souq Waqif, Aspire Zone, and the Corniche waterfront area which received $57 \%, 56 \%$, and $49 \%$ respectively. This suggests a strong interest, by the respondents, in culture and sports, which are specific attributes of these particular spaces. The result could be attributed to the fact that these places offer a wide variety of facilities, functions and activities including cultural events and art exhibitions, and in the case of Katara 


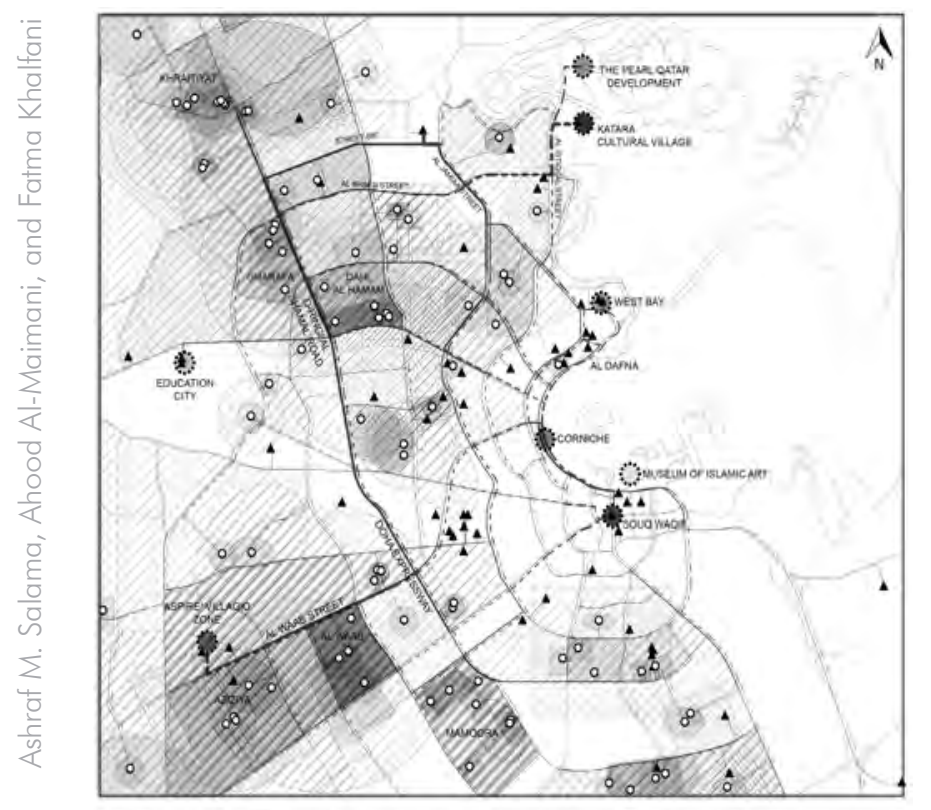

- Home Location Home Zone Home Range 4 Work Location U Urban Space

Note: Cumulatve mapping of fesponcents to home zone and home range is shown in dark shacec areas Route taken to work.

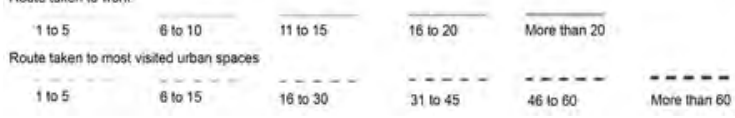

Figure 6.Cumulative mapping of respondents' reactions to geographical location and movement across the city (Source: Authors).

Cultural Village and Souq Waqif, ethnic restaurants and cafés; the study also indicates a preference for enjoying the outdoors in the green spaces and walking/pedestrian areas around the sports complex of Aspire Zone/Villagio and the tree-lined waterfront park and pedestrian spine along the Corniche.

Two areas appear to be of no interest to the respondents as most visited urban spaces; these are the Museum of Islamic Art Park (1\%) and Education City (4\%). Insufficient parking space, both inside and outside the museum boundaries, and the controlled accessibility to the gated museum gardens, in addition to the limited opening hours could be factors that discourage public interest in visiting. However, recently the MIA Park has been receiving more visitors; this may be due to the recent establishment of two cafés and a children's play area in addition to extended evening opening hours. Education City is an exclusive gated campus community that requires permission to enter; it also does not have activities that cater to the general public and as such does not encourage visiting by the public. It should be noted, however, that Education City does provide specialised activities of interest to academics and researchers.

\section{Home Range, Home Zone and Movement}

Mapping the respondents' identification of home and work locations, home zones, home ranges, and the routes taken from living areas to work areas reveals interesting findings (Figure 6). Based on the responses, the distribution of homes clearly reflects the fragmented nature of the city where residential areas are located far from the business or commercial districts. This echoes the preference of the respondents to reside away from the centre core, most specifically in the northwest and southwest of the city.

The perception of home zone is rather varied as some respondents depict it as an undefined bubble while others portray it with clearly defined perimeters or boundaries. The responses with regard to home locations and home zones reveal three major areas that can be considered home zones for the participants: these are Al Waab, Dahil Al Hamam, and Khraitiyat. Responses to home range also vary with regard to size of representative areas and the demarcation of boundaries. Notably, the cumulative mapping and the intersection of home ranges show specific residential areas as representative of home ranges for the respondents. Areas of significance include Mamoura, Al Waab, Azizya, Dahil Al Hamam, Madinat Khalifa, and Gharrafa (Figure 6).

The distant location of certain residential areas could also reflect difficulties with mobility and access across the city. Interestingly, the concentration of private sector residential areas seems to be moving toward the West Bay; the new business and financial district. This trend could eventually initiate better access routes to the residential areas located northwest of the city, in addition to benefiting businesses because of the closer proximity to certain governmental institutions that have recently relocated to the West Bay area.

The results of mapping the respondents' indications of roads and routes taken to work areas and to the most visited places reveal significant findings. For example, D-Ring Road, as part of the new Doha Expressway which later merges into Al Shamal Road, appears to be the most commonly used route for respondents to reach their workplace (Figure 6). This is likely due to its connectivity as a main artery to the most important areas of the city. Its vehicular capacity and flow of movement makes it an important urban transport spine that links different parts of the city.

In addition, routes taken to some of the most visited spaces appear as logical access points from nearby residential communities, as for instance, Al Waab Street, which crosses Al Furusiya Road, a major artery that separates Doha from the neighbouring city of Al Rayyan, emerges as a major spine. Al Waab Street starts from the southwest edge of the city, runs along and by Aspire 


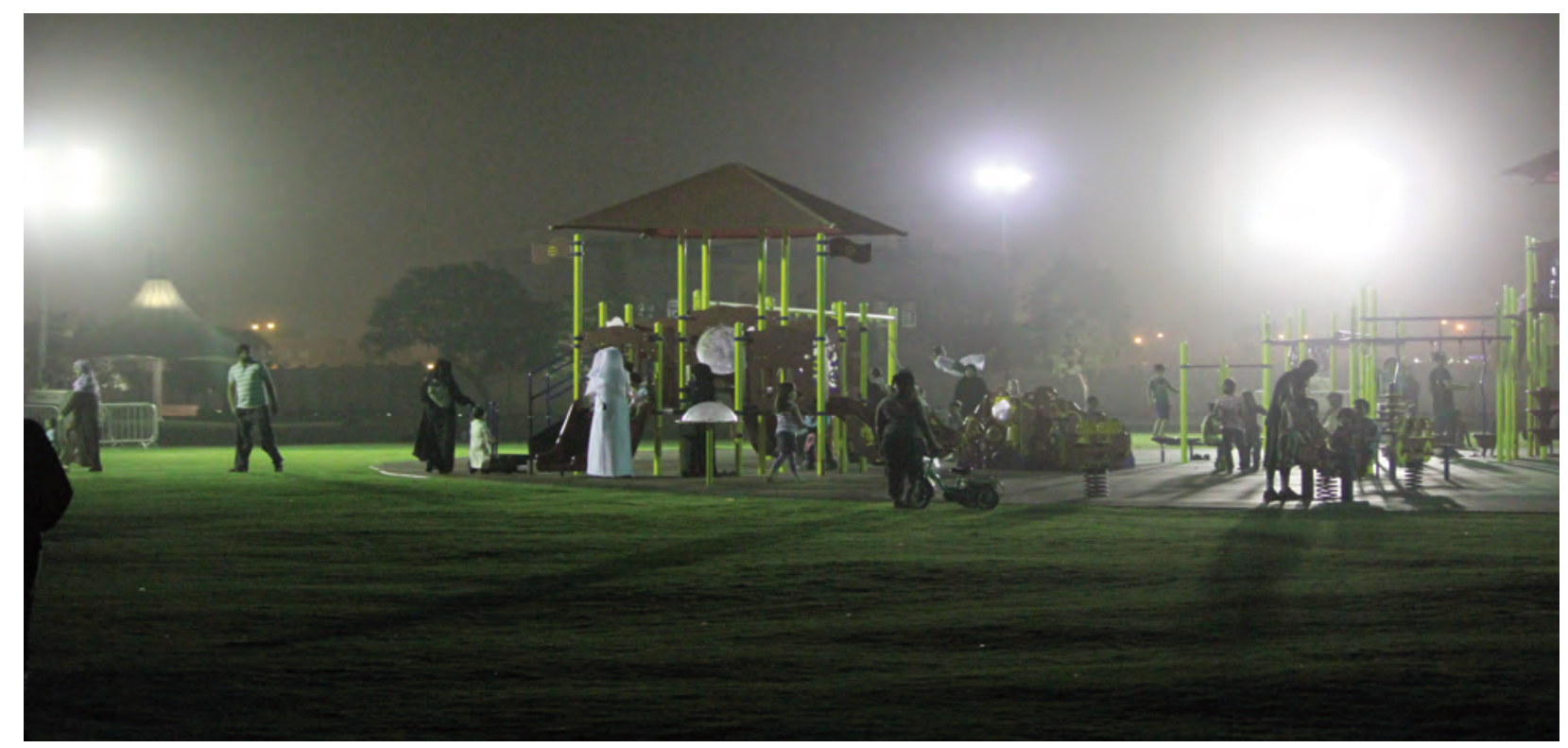

Figure 7. Aspire Park, a key attraction of Qataris in the sample surveyed. (Source: Authors).

Zone/Nillagio, and then connects to the Doha Expressway. The expressway eventually merges to become Al Shamal Road, the main highway to the north of the country. The eastern end of Onaiza Street, which passes alongside Katara Cultural Village and The Pearl Qatar en route to Lusail City - a major development project, also appears as an important spine. While a considerable number of alternative routes are used extensively by many
Doha residents, especially those that are parallel and to the east of Al Shamal Road, these do not seem to be much used by the respondents.

\section{Ethnic Affiliation: Qataris and Arab Expatriates}

A number of usage and destination differences were found in the responses of Qataris compared to other Arab expatriates, for example, Aspire/Villagio Zone (Figure 7), Katara Cultural

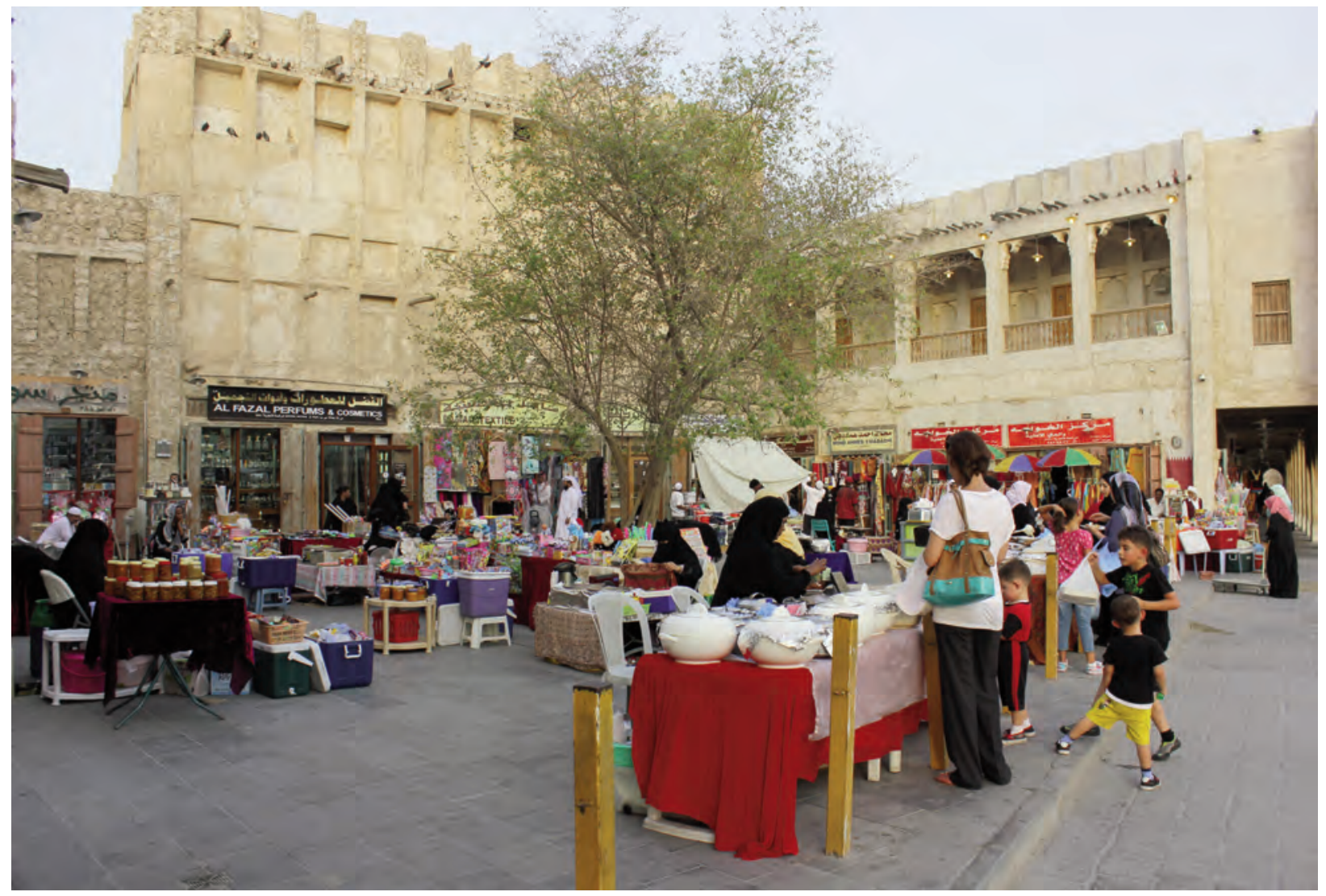

Figure 8. Souq Waqif, a key attraction of Arab expartiates in the sample surveyed. (Source: Authors). 


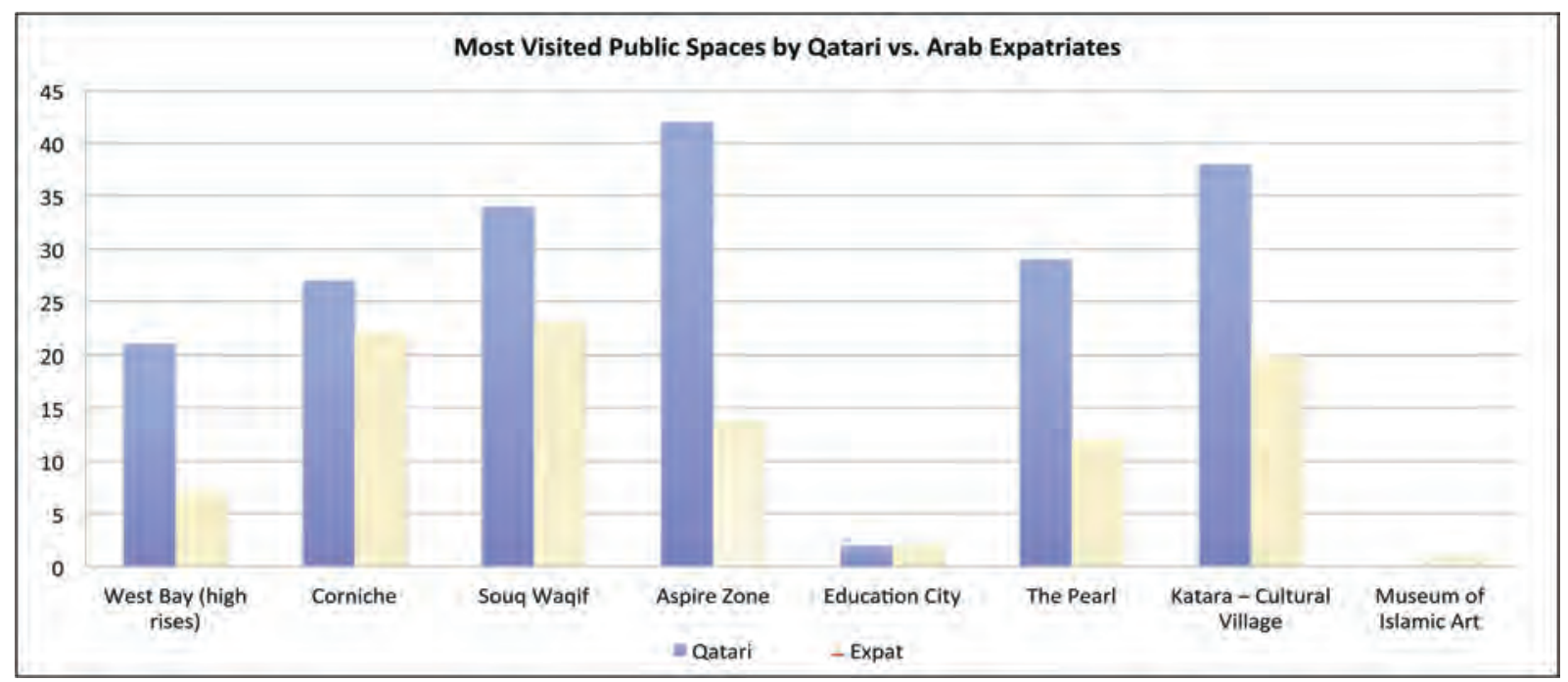

Figure 9. Most visited public spaces by Qatari vs. Arab expatriates respondents. (Source: Authors).

Village, and Souq Waqif appear to be the most visited urban spaces for Qatari respondents, receiving $42 \%, 38 \%$, and $34 \%$ respectively. In contrast, Souq Waqif (Figure 8), the Corniche, and Katara Cultural Village were identified as the most visited by Arab expatriate respondents, receiving 23\%, 22\%, and $20 \%$ respectively. Both groups agreed on the least visited urban spaces: Education City and the Museum of Islamic Art Park. In essence, these results reflect the preference of both groups to visiting urban spaces that are closer to their residence. Since the majority of Qatari respondents live in the northwest or southwest part of the city, they usually visit urban spaces like Katara Cultural Village and Aspire Zone that are in close proximity to where they reside. As Arab expatriate respondents tend to live closer to the centre core, their two most visited places, Souq Waqif and the Corniche waterfront area, are also closer to the centre; however, Katara Cultural Village rated as the third most visited urban space, is just a few kilometres further north of the centre (Figure 9).

In generic terms, there is no clearly defined area for Qatari respondents of a significant dense concentration representative of their interests with regard to their perception of home zones and home ranges (Figure 10). The Qatari respondents are more distributed and reside further away from the centre core, around the peripheries of the city in areas where their requirements are more easily met with the availability of larger properties, bigger houses and more private space. In contrast, for Arab expatriates, home zones and home ranges are much more clearly defined and are larger in size and area as evidenced in the cumulative responses (Figure 11).

Home ranges indicative of residential segregation are evident in Khraitiyat and south of the Al Waab area; these areas are more exclusive to $-44$
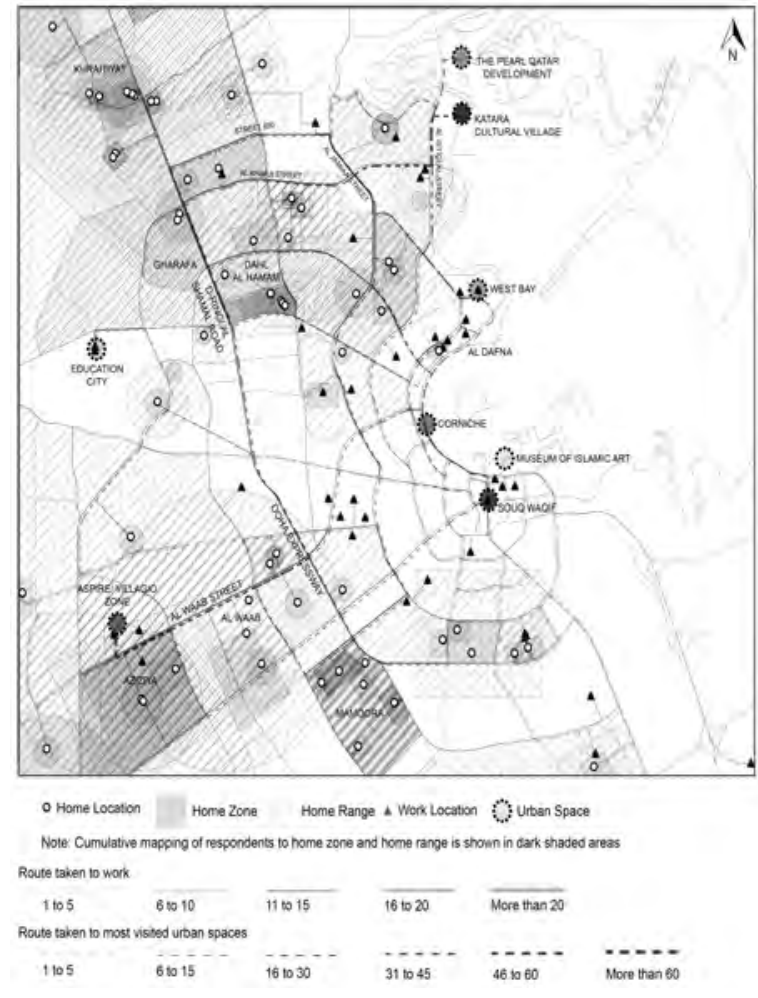

Figure 10. Cumulative mapping of Qataris' reactions to geographical location and movement across the city. (Source: Authors).

Qataris while the Al Sadd area, the Al Waab area, and the city centre are more typical residence areas for most Arab expatriates. Some areas, however, are more inclusive, with a fair mix of Qatari and Arab expatriates; these include Mamoura, Gharrafa, and Dahil Al Hamam. The latter two areas, however, have recently witnessed the introduction of new residential compounds that accommodate a considerable segment of expatriates, thus making them more mixed than they were a few years ago. In contrast to the results of mapping 


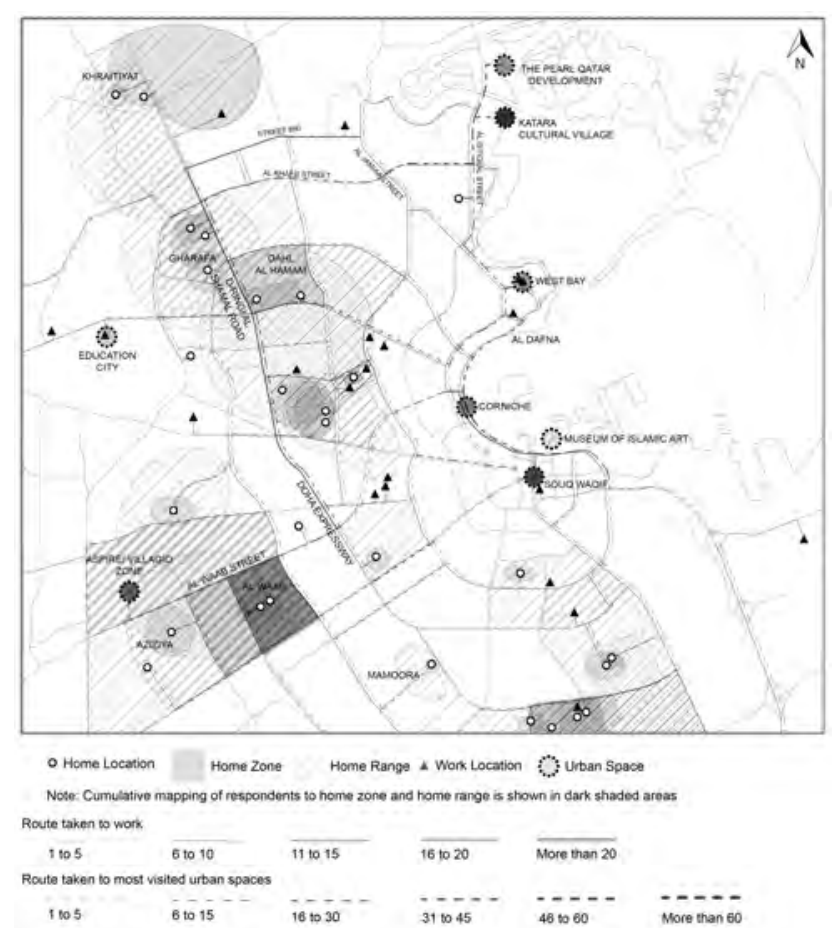

Figure 17. Cumulative mapping of Arab expatriates' reactions to geographical location and movement across the city. (Source: Authors).

home ranges, work location for Qataris seems to be closer to the city centre while for Arab expatriates it is more varied and may be distributed around the centre, and the Al Sadd area, as well as in other parts of the city. This pattern may reflect the fact that most Qataris work in the ministries and government institutions located in the centre or in close proximity to it, while the expatriate Arabs work in more diverse areas and neighbourhoods located in various parts of the city and its peripheries.

In the category based on cultural backgrounds as to which routes are most frequently used to reach work areas or access most visited urban spaces, no major differences were found. DRing Road and Al Shamal Road/The Doha Expressway appear to be the arteries most often used by both groups to reach their work areas. In addition, for Qataris there is heavy usage of $\mathrm{Al}$ Waab Street to reach their most visited urban spaces. Arab expatriates, however, appear to have a preference for the Corniche route to reach their most visited urban spaces. This may be due to the fact they offen work and reside in closer proximity to these spaces.

\section{CONCLUSIONS}

The lack of previous empirical studies to explore urban spaces in the city of Doha (Ahmadi, 2008; Salama, 2011), which this work could have built upon, represents one of the limitations of this research. However, the findings generated from implementing cognitive mapping and attitude survey combined have helped contribute to a more indepth understanding of the inhabitants' spatial experience of the city of Doha.

By establishing a knowledge base derived from direct experience of inhabitants including movement patterns and the rhythm of geographical locations within the city, the various aspects of how certain areas work within the urban structure of the city can be elucidated. A number of factors appear to contribute to recognize-ability of places. This includes a) proximity, where nearby places tend to be more familiar to people than places that are distant; b) size, where large places tend to be better known such as the Aspire Zone than small places; c) location, where places on the border such as the waterfront promenade are better known than places in the interior, especially if they have no distinctive features; d) character, where places with a distinctive form and character such as Katara Cultural Village are more easily recognized; and e) social-cultural aspects, where places with an important history or cultural distinction are better known such as Souq Waqif or the Museum of Islamic ArtMIA.

The findings of implementing cognitive mapping based survey reveal that inhabitants have different experiences of the city and its urban open spaces and that their mental images and experiences determine the degree to which they react to the qualities of those spaces. Such qualities can be seen as factors impacting the liking, visiting, and passing by of spaces. In generic terms, urban spaces in Doha appear to be favoured by most respondents: certain spaces, however, have poor or substandard attributes, which need improvement in order to enhance user experiences.

While offering important insights, it should be noted that the preceding aspects pertinent to the urban environment of Doha do not represent the full spectrum of issues related to the dialectic relationship between people and their environment. In this respect, introducing the concept of the quality of urban life should be seen as a necessity where issues related to satisfaction, well being, happiness are understood with relevance to the spatial quality of public spaces and the overall experience of the urban environment of the city. Whereas future development plans of the city may appear to address specific groups and cater to specific age 
groups or cultural backgrounds, a more responsive and inclusive approach to the design of urban spaces needs to be put in place.

\section{ACKNOWLEDGEMENT}

This study is developed as part of a comprehensive funded research project of the National Priorities Research Program, QNRF-Qatar National Research Fund (NPRP 09 - 1083 - 6 - 023).

\section{REFERENCES}

ABDEL-HADI, A., ELNACHAR, E. and SAFIELDIN, H. 2011. Residents' Perception of Home Range in Cairo, in Open House International, 36(2), 59-69.

AHMADI, A. 2008. The Urban Core of Doha: Spatial Structure and the Experienced Centre, MSc Thesis in Advanced Architectural Studies, University College London, London.

ALTMAN, I. 1975. The Environment and Social Behavior. Brookes/Cole, Monterey, CA.

BURGESS, E. W. 1925. The Growth of the City, in R.E. Park, E. W. Burgess, and R. D. McKenzie (eds.), The City: Suggestions of Investigation of Human Behavior in the Urban Environment, University of Chicago Press, Chicago, IL. 47--62

DOWNS, R. M. and STEA, D. 1973. Image and environment: Cognitive mapping and spatial behavior. Aldine Publishing Co, Chicago, IL.

GEYER, H. S. and KONTULY, T. M. (eds.) 1996. Differential Urbanization: Integrating Spatial Models. Routledge, London.

ORMROD, J. E. 2011. Human learning. (6th ed.). Pearson/Prentice Hall, Upper Saddle River, NJ.

RAPOPORT, A. 2006. Culture, Architecture, and Design, Locke Science Publishing Co., Chicago, IL.

SALAMA, A. M. 2011. A Dialogical Understanding of Urban Center(s) and Peripheries in the City of Doha, Qatar, in Architectural Humanities Research Association: Peripheries 2011 , Queen's University, Belfast.

SALAMA, A. M. and GHARIB, R.Y. 2012. A Perceptual Approach for Investigating Urban Space Diversity in the City of Doha, in Open House International, 37(2), 24-32.
SALAMA, A. M. and WIEDMANN, F. 2013. Demystifying Doha: On Architecture and Urbanism in an Emerging City. Ashgate Publishing Ltd., Surrey.

SOROKIN, P. 1927. Social Mobility. Harper, New York, NY.

\section{Author(s):}

Prof. Ashraf M. Salama

Professor of Architecture and Urbanism

Head, Department of Architecture and Urban Planning, Qatar University.

Email: asalama@qu.edu.qa

\section{Ahood Abdullah Al-Maimani}

Postgraduate Student - Master of Urban Planning and Design, Department of Architecture and Urban Planning, Qatar University.

Email:200662469@qu.edu.qa

\section{Fatima Abdulla Khalfani}

Postgraduate Student - Master of Urban Planning and Design, Department of Architecture and Urban Planning, Qatar University.

Email:200464524@qu.edu.qa 